\title{
Influência das Variáveis de Operação do Sistema de Alimentação de Pó de Prensa Sobre a Densidade Aparente
}

\author{
J. M. Tiscar ${ }^{a}$, J. Boix ${ }^{a}$, G. Mallola ${ }^{a}$ J. Montolio ${ }^{a}$, L. Foucarda, R. Bonaque ${ }^{b}$, J.A. Pérez \\ a Instituto de Tecnología Cerámica - ITC, Asociación de Investigación de las Industrias Cerámicas - AICE, Universitat Jaume I, \\ Castellón, España \\ ${ }^{b}$ MACER S. L. \\ *e-mail: boixjuan@hotmail.com
}

\begin{abstract}
Resumo
O carregamento das cavidades do molde durante a etapa de conformação dos substratos é uma etapa crítica do processo de fabricação das placas cerâmicas, que afeta muito as características do produto final. Este trabalho analisa, pela primeira vez, e de forma sistemática, o efeito das variáveis de operação do sistema de alimentação sobre a distribuição do pó nas cavidades do molde. A experimentação foi realizada sobre um banco de provas que permitiu avaliar o efeito das variáveis de operação sobre a distribuição da densidade aparente, espessura e massa do leito de pó dentro de um alvéolo de dimensões $30 \mathrm{~cm} \times 60 \mathrm{~cm}$ e com profundidade variável. A análise da distribuição de densidade aparente e da massa do leito de pó atomizado depositado na cavidade foi feita pela técnica não destrutiva de absorção de raios X.
\end{abstract}

Palavras-chave: pó atomizado, sistema de alimentação de prensa, densidade aparente, absorção de raios X.

\section{Introdução}

O sistema de alimentação de pó atomizado nos alvéolos do molde é um dos elementos do equipamento de prensagem que menos evoluiu nas últimas décadas. Apesar das prensas destinadas à conformação de placas terem evoluído consideravelmente, desde as antigas prensas à fricção às atuais prensas hidráulicas em somente 30 anos, o sistema de alimentação de pó apresenta, atualmente, o mesmo projeto conceitual daqueles utilizados nos anos 1970 [1].

Em sua concepção mais simples, o sistema de alimentação de pó (Figura 1) é composto, por um lado, de um alimentador de dosagem (ou funil, tradicionalmente fixo) que nos últimos anos foi progressivamente substituído por um dispensador móvel, à medida que o tamanho das peças fabricadas foi aumentado. Por outro lado, o sistema de transporte consiste de uma rede metálica, conhecida como "grade ou grelha". Tal rede pode ter diferentes formas geométricas dependendo do fabricante e/ou das necessidades do usuário. O sistema de alimentação assim constituído permite transportar às cavidades do molde, pelo movimento longitudinal da rede ("grade") sobre a matriz do molde, o pó atomizado depositado previamente nesta pelo dispensador.

Durante cada ciclo de carregamento a parte frontal da grade deposita sobre o plano de rolos, situado na saída da prensa, as peças conformadas no ciclo de prensagem anterior. Ao mesmo tempo, o pó necessário para conformar as peças seguintes cai nos alvéolos do molde, no momento em que se formam tais alvéolos como consequência do deslocamento dos punções inferiores da prensa até a posição da primeira queda (batida). Em seu movimento de retrocesso até a posição de carregamento, a grade nivela o pó depositado nos alvéolos, deixando a superfície do leito de pó pronta para receber o esforço axial de compressão correspondente. Finalizado o ciclo de compactação, a subida dos punções inferiores permite extrair do molde as peças conformadas, que são novamente empurradas pelo sistema de alimentação, iniciando-se, deste modo, um novo ciclo de prensagem.

Uma distribuição de pó heterogênea durante o carregamento do alvéolo origina, no leito resultante, diferenças de densidade, que se traduzem em diferenças de densidade aparente na placa conformada. Posteriormente, durante a queima, se estas diferenças forem excessivamente grandes, são produzidos, com frequência, defeitos de falta de ortogonalidade conhecidos como "desquadros" [2].

Historicamente, a falta de homogeneidade na distribuição do pó foi compensada colocando-se, entre os punções e a travessa que os sustenta, pequenas lâminas metálicas que redistribuem a pressão no meio da peça para compensar as diferenças de carga. Mais recentemente apareceram no mercado os conhecidos punções isostáticos, nos quais há um leito de óleo entre o recobrimento polimérico do punção e a placa metálica que constitui o punção propriamente dito. Esta câmara de óleo permite redistribuir, sem a necessidade de acrescentar suplementos metálicos, as pressões sobre o leito de pó, com o objetivo de se obter uma distribuição homogênea da densidade aparente no interior de cada placa. As soluções propostas para resolver os problemas associados a uma má distribuição do pó no meio dos alvéolos da prensa não agem diretamente sobre a distribuição do pó no molde. Todas as soluções propostas 


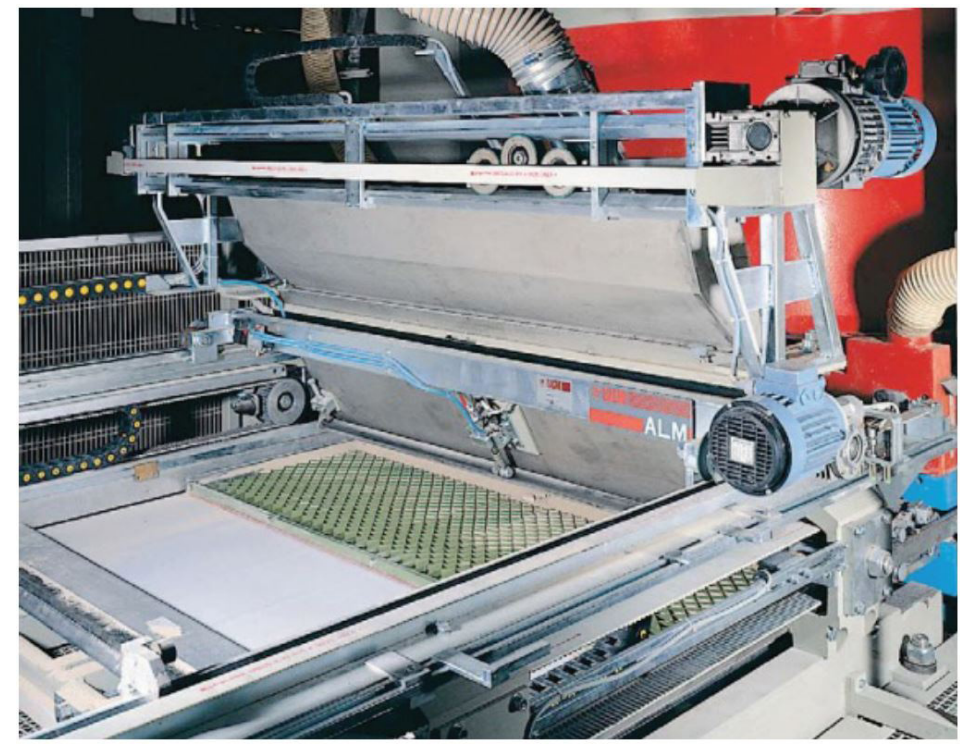

Figura 1. Sistema de alimentação de pó atomizado empregado em prensas industriais de conformação de placas cerâmicas.

até o momento têm um caráter passivo, ao compensar as deficiências de carregamento pela redistribuição da pressão aplicada sobre o leito de pó. Esta forma de proceder não é totalmente satisfatória, pois, industrialmente, continuam aparecendo problemas de "descuadro".

Para resolver este problema, também foi proposta a simulação do carregamento dos moldes pelo método dos elementos discretos (MED) [3], como uma alternativa para estudar como as variáveis de operação afetam a distribuição dos pós nos alvéolos. Pela simulação é possível estudar a microestrutura do pó depositado no molde diretamente, sem a necessidade de experimentação [4,5]. No entanto, o custo computacional deste método é consideravelmente elevado, não sendo possível obter, até o momento, resultados quantitativos. Mas, a riqueza da informação qualitativa proporcionada por estas ferramentas de simulação, junto com as outras ferramentas de caracterização como a análise não destrutiva por raios $\mathrm{X}$, abrem portas para o projeto sistematizado e otimizado de novos sistemas de alimentação de pó.

Desta forma, o objetivo principal deste trabalho foi conhecer o efeito das diferentes variáveis de operação do processo de preenchimento do molde sobre as propriedades do leito de pó resultante. As variáveis de operação cujo efeito foi estudado são: a velocidade da grade, o instante da queda do punção inferior e a espessura da carga.

\section{Materiais e Procedimento Experimental}

\subsection{Materiais e equipamentos}

Para a realização do estudo foi empregado um pó atomizado normalmente utilizado para a fabricação de placas de grés porcelanato esmaltado. A distribuição granulométrica do mesmo se ajusta a uma distribuição

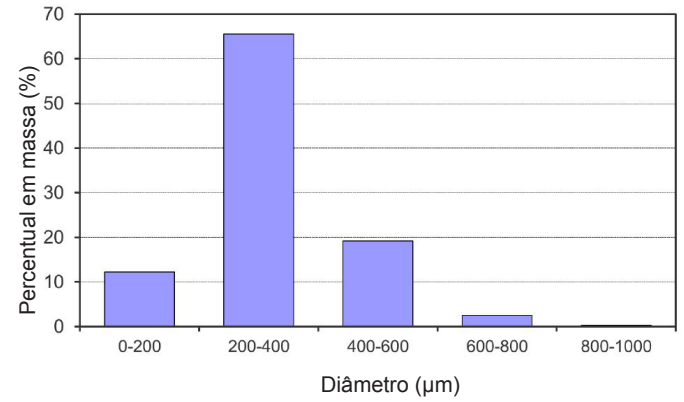

Figura 2. Distribuição de tamanho dos grânulos do pó atomizado empregado na realização do trabalho.

normal logarítmica com uma média geométrica $\left(\mu_{\text {geo }}\right)$ de $300 \mu \mathrm{m}$ e um desvio padrão geométrico $\left(\sigma_{\text {geo }}\right)$ de 1,43. A Figura 2 mostra a distribuição de tamanho dos grânulos do pó empregado. O pó utilizado é um pó seco, com o objetivo de eliminar o impacto da umidade nos resultados obtidos.

Para estudar a influência das variáveis de operação sobre o processo de enchimento do molde, foi desenvolvido e construído um sistema de alimentação de pó em escala piloto (Figura 3). No protótipo construído distinguem-se alguns elementos: um pré-alimentador (1), um funil de alimentação (2), uma grade intercambiável (3), um molde com um único alvéolo de tamanho $30 \mathrm{~cm} \times 60 \mathrm{~cm} \mathrm{(4)} \mathrm{e}$ o sistema de controle para programar o movimento dos distintos elementos do sistema de alimentação (5), como ocorre em uma prensa industrial.

Para realizar o ensaio de carregamento, o pó atomizado é colocado no interior do pré-alimentador e deste transferido para o alimentador inferior, retirando-se manualmente a 


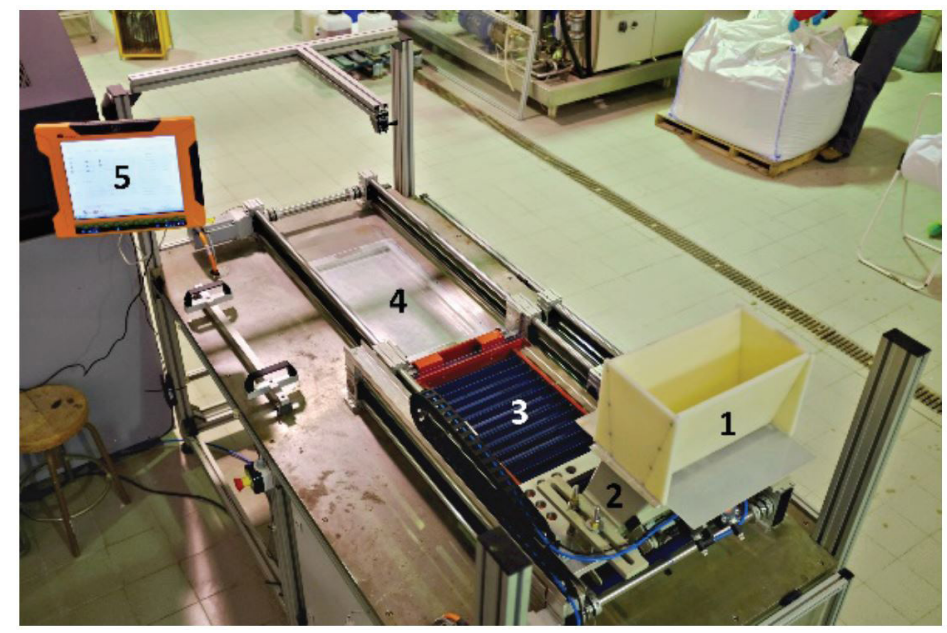

Figura 3. Banco de provas piloto para a análise do carregamento de moldes para fabricação de placas cerâmicas.

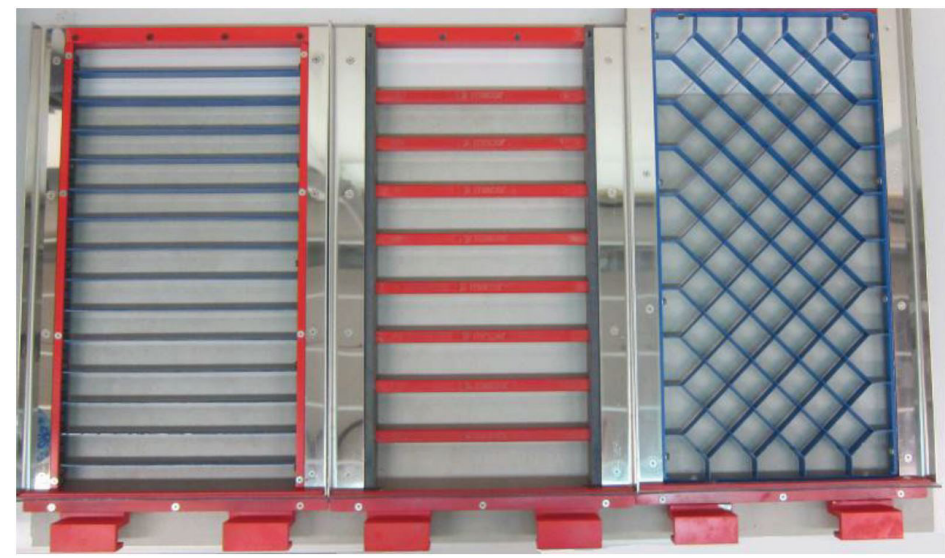

Figura 4. Grades flutuantes empregadas no estudo. Esquerda: grade de lâminas; centro: grade de raspadores; direita: grade de "favos de mel".

comporta que os separa. Assim procedendo se reduz a influência do operador sobre a distribuição do pó contido no alimentador. Assim que o alimentador está cheio, o ciclo de carregamento da grade é iniciado, de acordo com o ciclo de alimentação definido pelo sistema de controle. Para os ensaios realizados neste trabalho sempre foi utilizado o mesmo procedimento de carregamento da grade.

Em primeiro lugar, o alimentador é deslocado até a parte dianteira da grade. A seguir, faz-se a abertura automática da comporta do alimentador e se inicia o retrocesso do mesmo até sua posição inicial, depositando o pó sobre a grade. Com a grade completamente cheia o ciclo de carga é feito de forma similar ao de uma prensa industrial.

No trabalho foi estudada a influência de três configurações distintas da grade sobre a distribuição do pó no alvéolo: uma grade flutuante com lâminas longitudinais, uma grade flutuante com raspadores em V (que para todos os efeitos são lâminas longitudinais de maior espessura e em forma de cunha), e uma grade flutuante com lâminas quadradas em diagonal conhecida como "favo de mel" (Figura 4). São consideradas grades flutuantes aquelas montadas sobre um quadro impermeável, o qual é apoiado sobre a placa de deslizamento do molde. Estes três projetos correspondem aos tipos de grades mais comuns utilizados industrialmente no momento.

\subsection{Inspeção radiológica dos leitos de pó}

Para analisar as características dos leitos de pó resultantes dos ensaios de carregamento realizados no protótipo, foi empregada uma técnica não destrutiva baseada na absorção de raios X. Ao se finalizar cada ensaio de carregamento utilizando um sistema de extração especialmente projetado, as lâminas e o fundo do alvéolo contendo o pó depositado eram extraídos. O conjunto assim formado era transportado até o equipamento denominado DensExplorer ${ }^{\circledR}$ (Figura 5) que permite medir a distribuição da densidade aparente, da espessura e da massa do leito de pó [6]. 


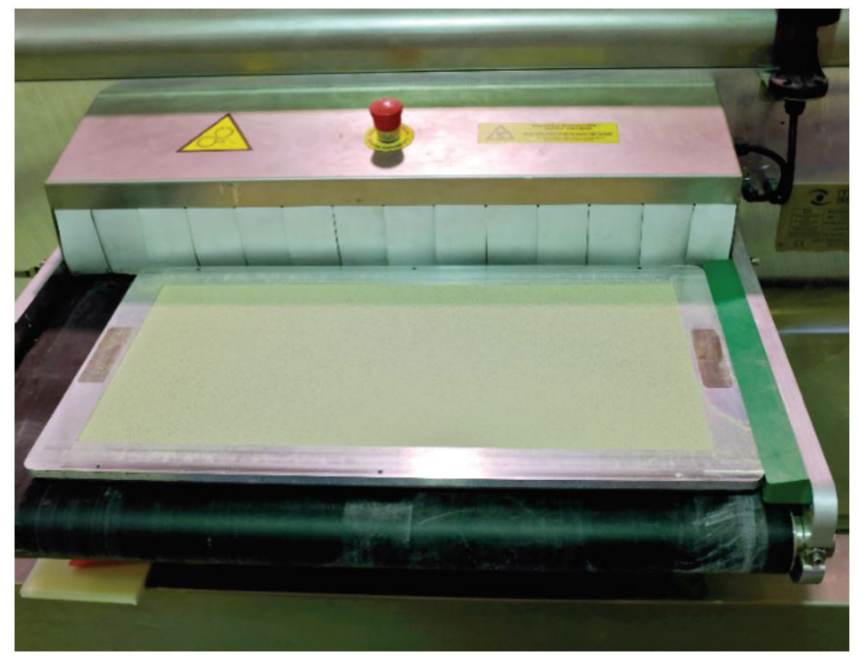

Figura 5. Equipamento de inspeção radiológica DensExplorer ${ }^{\circledR}$ empregado para analisar as características físicas dos leitos de pó.

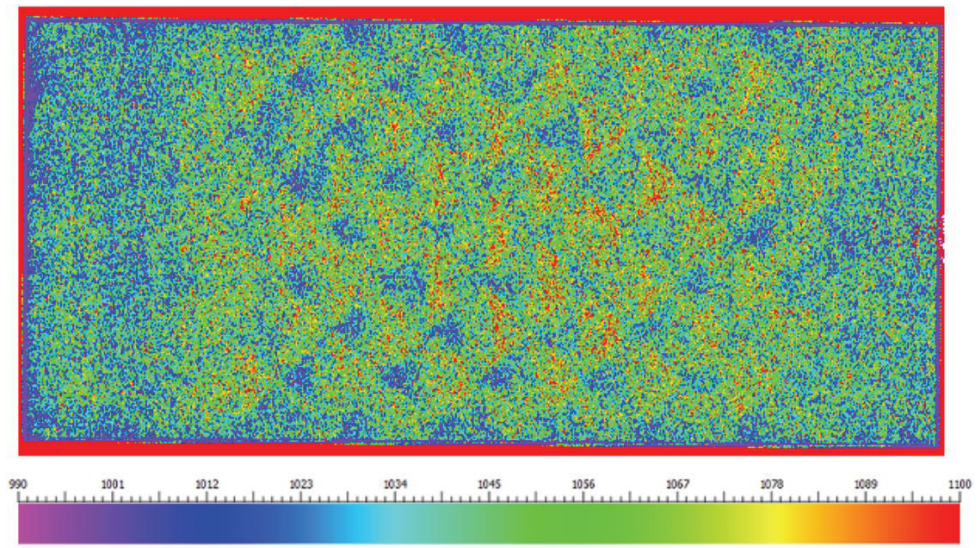

Figura 6. Mapa de distribuição da densidade aparente $\left(\mathrm{kg} / \mathrm{m}^{3}\right)$ de um leito de pó preparado com o protótipo.

O equipamento empregado mede diretamente a espessura e a absorção de radiação em cada ponto da superfície do material analisado, para, posteriormente, calcular a densidade aparente e proporcionar um mapa da distribuição da densidade aparente em cor falsa (Figura 6). O cálculo da densidade aparente está baseado na lei física de Beer-Lambert [7], e requer para sua utilização um trabalho prévio de calibração.

A calibração do equipamento consistiu em se analisar vários leitos de pó de espessuras diferentes preparados com o mesmo pó atomizado usado nos ensaios de carregamento. Como os leitos de pó resultantes dos ensaios realizados no protótipo estavam depositados sobre o fundo metálico do alvéolo, os leitos de pó empregados na calibração também foram preparados sobre o mesmo material. Para isto foram confeccionados quatro recipientes cilíndricos de alturas diferentes e mesmo fundo metálico que o alvéolo piloto, e em seu interior foi depositado o pó por queda livre (Figura 7). A superfície de cada leito foi nivelada cuidadosamente com uma espátula e sua densidade aparente foi determinada a partir de seu volume e da massa de pó empregada. Analisando-se as amostras com o equipamento foi possível obter-se a relação existente entre a capacidade de atenuação do material e a espessura e densidade do leito. Esta relação de calibração foi empregada para determinar os mapas de distribuição de densidade aparente dos distintos leitos obtidos com o protótipo.

\subsection{Planejamento experimental}

Para analisar a influência das variáveis de operação sobre a distribuição de pó, foi realizado previamente um planejamento experimental fatorial completo, para testar todas as possíveis combinações entre as variáveis de operação estudadas.

A Tabela 1 mostra o resumo das variáveis de operação experimentais e os níveis de variação. Tais condições de operação foram ensaiadas para as três tipologias de 


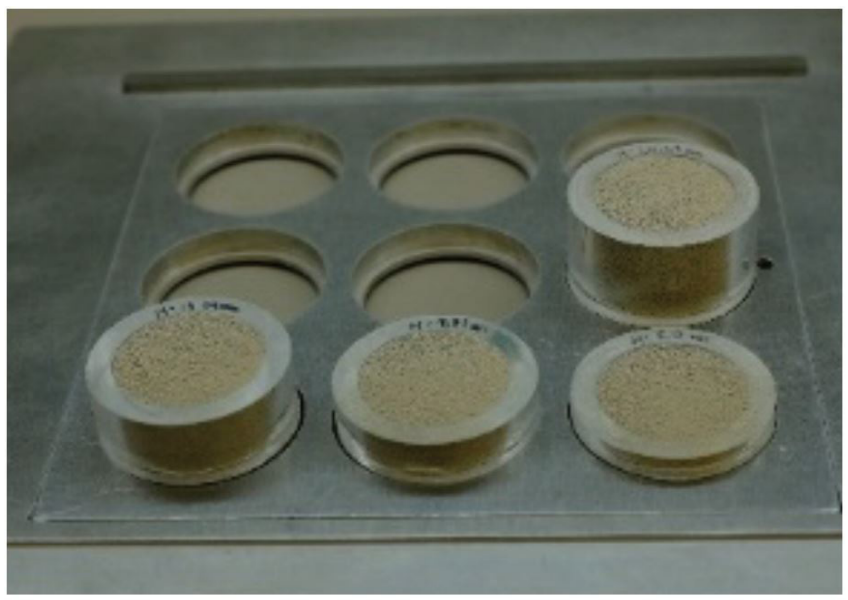

Figura 7. Amostras empregadas para a calibração do equipamento de raios X.

Tabela 1. Variáveis de operação e níveis utilizados no planejamento experimental.

\begin{tabular}{lccc}
\multicolumn{1}{c}{ Variável de operação } & Ref. & Nível (-) & Nível (+) \\
\hline Velocidade da grade (mm/s) & $\mathrm{Vp}$ & 660 & 1320 \\
Instante da queda do punção inferior (\%) & $\mathrm{Cp}$ & 60 & 90 \\
Espessura de carga (mm) & Esp. & 13 & 18 \\
\hline
\end{tabular}

grades disponíveis. O instante da queda do punção inferior foi definido de forma percentual em função da posição relativa da grade em relação ao início do alvéolo. Assim, por exemplo, um instante de queda a $0 \%$ significa que a queda do punção inferior ocorre no mesmo instante em que a parte frontal da grade coincide com a borda posterior do alvéolo.

Os limites de variação das variáveis foram eleitos para conter o intervalo de variação normalmente empregado em condições industriais. No total foram realizados 24 experimentos de enchimento/carregamento, modificando-se todas as variáveis estudadas com os três tipos de grades disponíveis. Após cada ensaio de carregamento, o leito de pó resultante foi transportado ao equipamento de inspeção radiológica e, a partir dos mapas de densidade aparente obtidos, foram determinados os perfis médios de densidade aparente ao longo do alvéolo. Em todos os resultados correspondentes aos perfis de densidade mostrados neste trabalho, a distância de $600 \mathrm{~mm}$ corresponde à parte frontal do alvéolo.

\section{Resultados e Discussão}

\subsection{Grade tipo "favo de mel"}

Em primeiro lugar, foi analisado o efeito das variáveis de processo utilizando a grade tipo "favo de mel". A Figura 8 mostra os perfis médios de densidade aparente correspondentes aos ciclos de carregamento obtidos nas distintas condições ensaiadas.
Para uma espessura de carga de $13 \mathrm{~mm}$ (Figura 8, esquerda), observa-se uma menor densidade aparente na parte dianteira do alvéolo, independentemente da velocidade de avanço da grade e do instante da queda do punção inferior. Este comportamento, que pode estar associado ao deslocamento do pó produzido pela grade durante o nivelamento do leito, é tão mais evidente quanto maior for a velocidade de avanço da grade e quanto mais tarde ocorre a primeira queda do punção. Para esta configuração, a distribuição mais homogênea da densidade aparente é obtida com uma velocidade da grade de $660 \mathrm{~m} / \mathrm{s}$ e um instante de queda do punção inferior de $60 \%$ (linha alaranjada no gráfico da Figura 8). Além disto, nestas condições é obtida a maior densidade aparente do leito. Em princípio, industrialmente são preferidos ciclos de carregamento que proporcionem as densidades de leito mais elevadas possíveis, pois, deste modo, a quantidade de ar a ser eliminado durante o ciclo de desaeração será menor. Isto repercutirá favoravelmente na qualidade do produto e na possibilidade de encurtar a duração dos ciclos de prensagem.

Com relação aos experimentos realizados para uma espessura de carregamento de $18 \mathrm{~mm}$ (Figura 8, direita), os valores de densidade aparente são mais homogêneos em todos os casos em relação àqueles para carregamento de $13 \mathrm{~mm}$. Como na configuração anterior, a densidade mais elevada e homogênea ocorre quando a velocidade da grade é de $660 \mathrm{~mm} / \mathrm{s}$ e o instante da queda do punção inferior é de $60 \%$. Deve-se destacar que, de forma distinta do que ocorre para espessuras de carregamento de $13 \mathrm{~mm}$, 

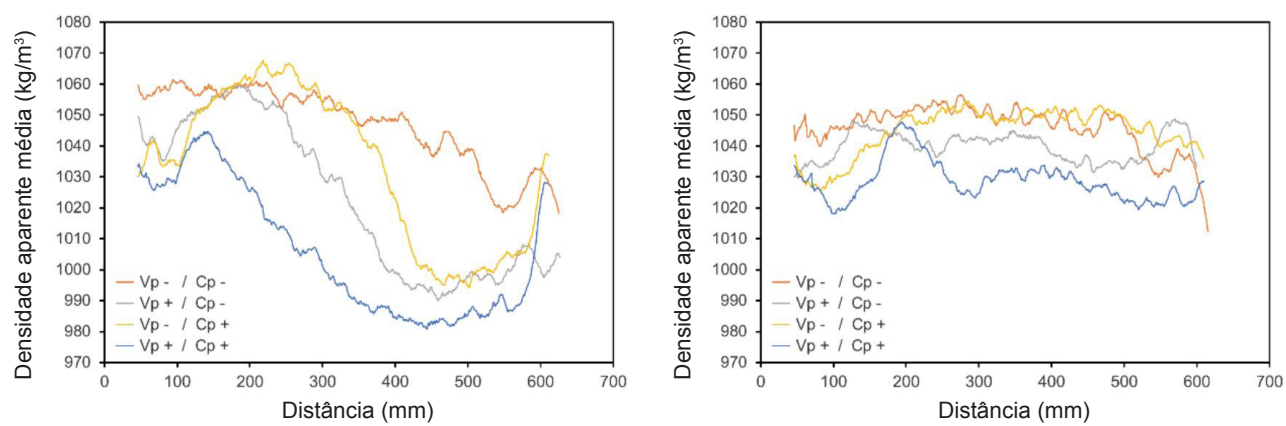

Figura 8. Perfis médios de densidade aparente correspondentes aos ciclos de carregamento com grade do tipo "favo de mel". Esquerda: espessura de carga de $13 \mathrm{~mm}$. Direita: espessura de carga de $18 \mathrm{~mm}$.
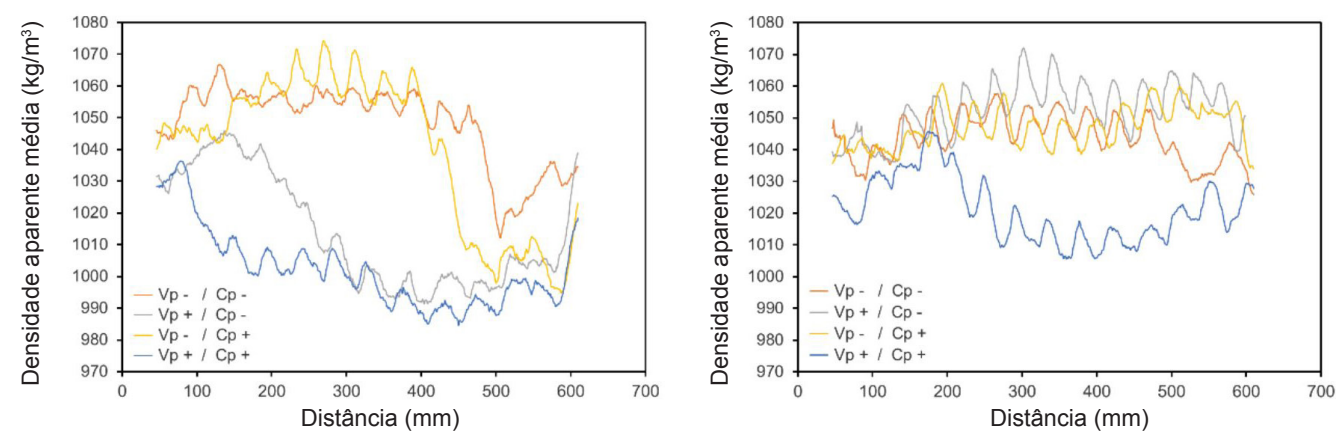

Figura 9. Perfis médios de densidade aparente correspondentes aos ciclos de carregamento com grade de lâminas. Esquerda: espessura de carga de $13 \mathrm{~mm}$. Direita: espessura de carga de $18 \mathrm{~mm}$.

com $18 \mathrm{~mm}$ as diferenças observadas entre os perfis de densidade são muito menos significativas. Além disto, o efeito do instante da queda dos punções é menos evidente, prevalecendo o efeito da velocidade de avanço da grade sobre a distribuição de densidade obtida. Este fato mostra que as distorções causadas pelo nivelamento do pó durante o retrocesso da grade têm menor incidência - são menos comuns - quanto maior for a espessura do leito.

\subsection{Grade de lâminas longitudinais}

A Figura 9 mostra os perfis médios de densidade aparente correspondentes aos ensaios de carregamento realizados com a grade de lâminas longitudinais. Com relação aos casos correspondentes a uma espessura de carregamento de $13 \mathrm{~mm}$ (Figura 9, esquerda), podem ser observadas tendências distintas. Por um lado, os resultados correspondentes a baixas velocidades da grade mostram densidades aparentes mais elevadas, embora com uma diminuição significativa da densidade na parte frontal do alvéolo, menos intensa quando a queda dos punções é produzida antecipadamente. Os resultados correspondentes a velocidades altas mostram o mesmo padrão de comportamento, mas com diferenças mais evidentes entre as partes dianteira e traseira do alvéolo. Este comportamento é análogo ao observado, para a mesma espessura de carregamento, ao da grade "favo de mel", embora, neste caso, a diferença entre os ciclos com velocidades diferentes seja mais significativa. De fato, para o caso da grade tipo "favo de mel" a zona de menor densidade aparente observada na parte frontal do alvéolo é reduzida de forma mais acentuada ao se diminuir a velocidade da grade e ao se adiantar a queda do punção.

Com relação aos ciclos de carregamento com espessura de enchimento de $18 \mathrm{~mm}$ (Figura 9, direita), todos conduzem a uma espessura de densidade aparente mais elevada e homogênea, com exceção do ciclo correspondente aos níveis altos de velocidade da grade e de instante de queda do punção inferior. Nestas condições concretas, os valores da densidade aparente são significativamente mais baixos e heterogêneos. Deve ser dada atenção ao carregamento realizado com uma alta velocidade da grade e um instante de queda do punção inferior de $60 \%$ (linha amarela), cujo perfil de densidade é aceitável por tratar-se de um carregamento realizado com uma alta velocidade de grade.

De modo diferente ao observado com a grade tipo "favo de mel", neste caso para espessuras de enchimento de $18 \mathrm{~mm}$ o efeito do instante da queda do punção afeta a distribuição do pó. Para uma elevada velocidade de avanço, se a queda do punção é atrasada (linha azul), a densidade na parte frontal do alvéolo é reduzida em aproximadamente $50 \mathrm{~kg} / \mathrm{m}^{3}$ em relação às outras condições. Estes resultados indicam que, em relação à grade "favo de mel" a grade de lâminas longitudinais causa maior distorção sobre a distribuição das densidades durante o nivelamento do leito de pó. 
Finalmente, é interessante destacar que os perfis de densidade aparente obtidos com a grade "favo de mel" apresentam menos oscilações que aqueles obtidos com a grade de lâminas. A análise dos perfis correspondentes à grade de lâminas mostra que a separação observada nas oscilações periódicas sobre a distribuição de densidades é da ordem de magnitude da separação entre as lâminas. Isto pode ocorrer devido a que a grade de lâminas provoca pequenas segregações locais dos grânulos de pó atomizado ao redor das lâminas separadoras, resultando em variações da densidade do leito de pó depositado. O fato de que não se observam oscilações tão marcantes com a grade "favo de mel" não significa que não existam variações de densidade devido ao efeito da grade (Figura 6). A razão daquelas não serem observadas nos perfis deve-se a que estes perfis são observações médias ao longo do eixo perpendicular à direção de carregamento. $\mathrm{O}$ comportamento observado explica porque, na indústria, ocasionalmente ocorrem defeitos estéticos no produto final sob a forma de marcas, na face aparente do produto, do tipo de grade empregada no alimentador.

\subsection{Grade de raspadores em V}

A Figura 10 mostra os perfis de densidade aparente correspondentes aos ciclos de carregamento realizados com a grade de raspadores em $\mathrm{V}$. Os ciclos correspondentes a uma espessura de enchimento de $13 \mathrm{~mm}$ (Figura 10, esquerda) mostram o mesmo comportamento que aquele observado com as grades anteriores, embora os valores de densidade global obtidos em cada ciclo sejam sequencialmente mais baixos. Como para as grades anteriores, este comportamento é associado à distorção originada durante o nivelamento do leito, cuja incidência no perfil de densidades é tão maior quanto menor seja a espessura de carregamento.

Com relação aos ciclos correspondentes a uma espessura de enchimento de $18 \mathrm{~mm}$ (Figura 10, direita), os valores obtidos para as densidades aparentes seguem sendo menores que para o caso das grades anteriores, embora se mantenha a tendência generalizada de se obter maiores valores de densidade aparente e uma maior homogeneidade quanto menor for a velocidade do sistema de alimentação. Ao mesmo tempo, como para o caso da grade de lâminas, para os ciclos com um nível alto de velocidade de grade, uma queda do punção inferior de $60 \%$ conduz a uma maior densidade na parte frontal do molde, em relação a uma queda de $90 \%$.

Finalmente, como no caso anterior, os perfis de densidade aparente contêm oscilações periódicas devido à forma dos raspadores. Neste caso as oscilações são mais intensas que no caso anterior, consequência da maior espessura dos raspadores em relação à das lâminas metálicas.

\subsection{Comparação dos mapas de densidade aparente}

Finalmente, como exemplo, a Figura 11 mostra mapas das densidades aparentes correspondentes aos leitos de pó obtidos com os três tipos de grade, com os ciclos de carregamento que levam a uma espessura de enchimento de $18 \mathrm{~mm}$ e um instante de queda do punção inferior de 90\%. Estas condições oferecem melhores distribuições de densidade aparente em comparação com os ciclos com uma espessura de enchimento de $13 \mathrm{~mm}$. Adicionalmente, foram representadas as condições de menor (Vp-, coluna esquerda) e maior velocidade da grade $(\mathrm{Vp}+$, coluna direita). Os valores numéricos mostrados sobre os mapas de densidade aparente correspondem aos valores médios de densidade aparente em cada um dos retângulos nos quais foram divididas as imagens.

Como foi demonstrado analisando-se os perfis médios de densidade aparente, em todos os casos a forma da grade reflete nos mapas de densidade aparente. Por outro lado, ao se aumentar a velocidade da grade é obtida menor densidade aparente em todos os casos, independentemente do tipo de grade utilizada. Porém, a grade "favo de mel" mostra ser a mais robusta, ao ser menos susceptível às mudanças produzidas pelas variáveis estudadas neste trabalho.

Finalmente, mostra-se o caráter simétrico do carregamento com relação ao eixo transversal, pois as principais variações na densidade aparente ocorrem ao longo do eixo horizontal do molde.
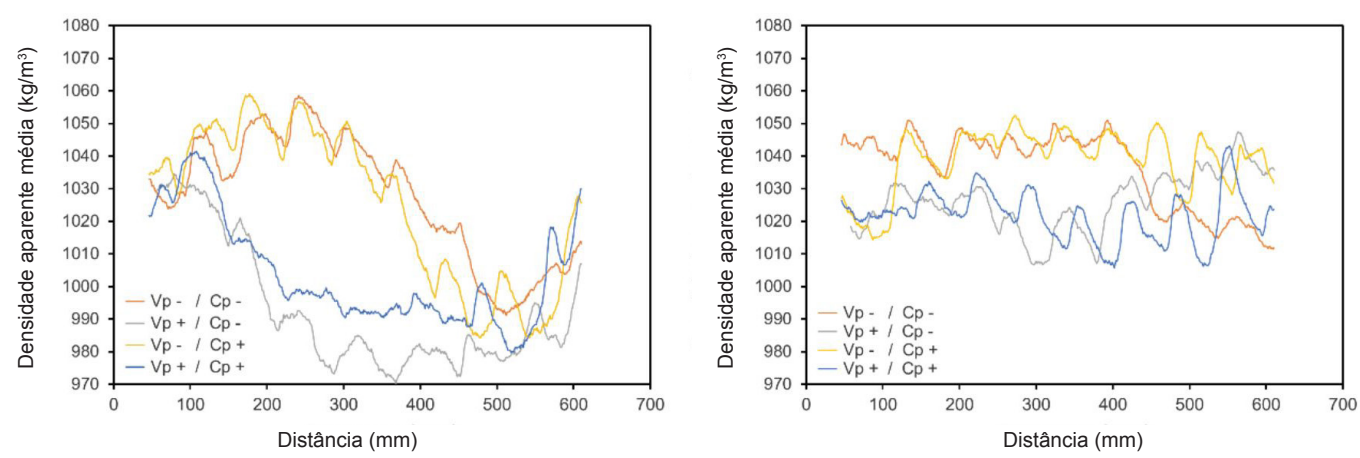

Figura 10. Perfis médios de densidade aparente correspondentes aos ciclos de carregamento com grade de raspadores em V. Esquerda: espessura de carga de $13 \mathrm{~mm}$. Direita: espessura de carga de $18 \mathrm{~mm}$. 


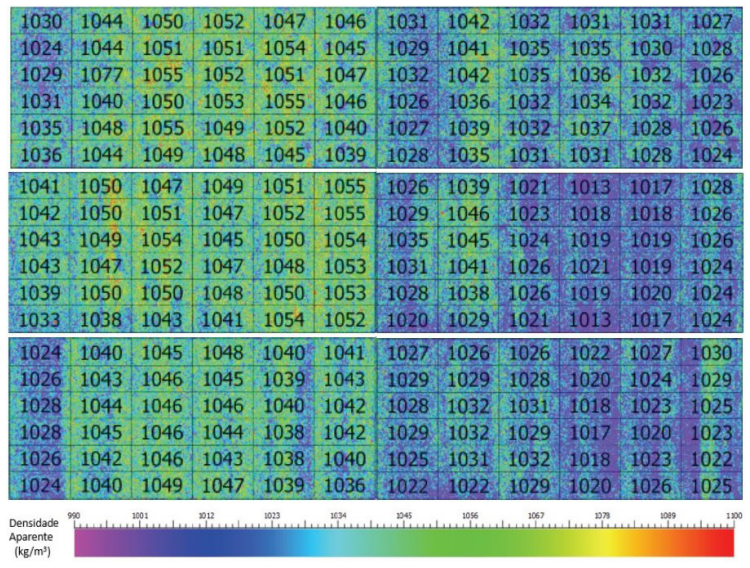

Figura 11. Mapas das densidades aparentes correspondentes aos ciclos ensaiados com uma espessura de enchimento de $18 \mathrm{~mm}$ e um instante de queda do punção inferior de $90 \%$. Coluna esquerda: Vp-. Coluna direita: Vp+. Superior: grade "favo de mel". Centro: grade de lâminas. Inferior: grade de raspadores em V.

\section{Conclusões}

Os experimentos realizados mostram o impacto das variáveis de operação consideradas para o enchimento dos moldes sobre as características do leito de pó depositado sobre os alvéolos e, portanto, sobre a qualidade do produto final. A seguir são detalhadas as conclusões do estudo realizado:

A espessura de enchimento influi decisivamente sobre o carregamento dos alvéolos. Quanto maior for a espessura de carregamento, a densidade aparente do leito depositado é muito mais homogênea e é menos influenciada pelas demais variáveis de operação. Contudo, esta variável é determinada pela espessura final da peça que se quer produzir.

A velocidade da grade afeta diretamente o perfil obtido da densidade final. Quanto maior for a velocidade da grade, menor é a densidade aparente do leito depositado, e mais heterogeneidades são mostradas pelo perfil de densidade resultante.

O instante da queda do punção inferior tem menos influência sobre a homogeneidade do carregamento do que a velocidade da grade. Seu efeito é importante para modificar a densidade aparente da parte dianteira do leito de pó, sobretudo quando a velocidade da grade é alta e quando são utilizadas lâminas longitudinais e raspadores em V.

A configuração geométrica da grade tem um efeito significativo sobre a distribuição do pó depositado. Quanto maior for a espessura de enchimento, maior é o efeito da forma da grade sobre a distribuição do leito de pó. Finalmente, quanto menor for a espessura das grades, menores são as oscilações de densidade aparente observadas no alvéolo.

\section{Agradecimentos}

Os autores agradecem ao Centro para o Desenvolvimento Tecnológico Industrial (CDTI) e ao Instituto Valenciano de Competitividade Empresarial (IVACE) o apoio econômico para esta pesquisa.

\section{Referências}

[1] R. Galindo Renau, Prensas, moldes y prensado en la fabricación de baldosas cerámicas, Macer, 2008.

[2] J. Amorós, V. Beltrán, A. Blasco, J. Enrique, A. Escardino, Defectos de fabricación de pavimentos y revestimientos cerámicos, Valencia, 1991.

[3] N. Bell, Y. Yu, P. J. Mucha, Particle-based simulation of granular materials, Proc. 2005 ACM SIGGRAPH/Eurographics Symp. Comput. Animat.

[4] J. Tiscar, A. Escrig, A. Pascual, F. A. Gilabert, R. Bonaque, J. A. López, Análisis de la operación de llenado del molde durante el proceso de prensado de baldosas cerámicas., in: Congr. Mund. la Calid. del Azulejo y del Pavimento Cerámico., Castellón, Spain, 2016.

[5] J. Tiscar, A. Escrig, G. Mallol, J. Boix, F.A. Gilabert, Influence of the die filling parameters during the ceramic tile pressing process via Discrete Element Method (DEM), in: Shap. VI, Sixth Int. Conf. Shap. Adv. Ceram., Montpeller, France, 2016.

[6] J. L. Amorós, J. Boix, D. Llorens, G. Mallol, I. Fuentes, C. Feliu, Non-destructive measurement of bulk density distribution in large-sized ceramic tiles, J. Eur. Ceram. Soc. 30 (2010) 2927-2936. doi:10.1016/j.jeurceramsoc.2010.01.033.

[7] D. F. Swinehart, The Beer-Lambert Law, J. Chem. Educ. 39 (1962) 333. 